BULLETIN Bulletin hispanique

HISPANIQUE Université Michel de Montaigne Bordeaux

117-1 | 2015

Les poètes des rhéteurs

\title{
El paisaje urbano moderno y la tradición literaria española
}

Visiones desde la torre en la obra de Clarín y Galdós

Álex Matas Pons

\section{(2) OpenEdition}

Journals

Edición electrónica

URL: https://journals.openedition.org/bulletinhispanique/3857

DOI: 10.4000/bulletinhispanique.3857

ISSN: 1775-3821

Editor

Presses universitaires de Bordeaux

Edición impresa

Fecha de publicación: 1 junio 2015

Paginación: 279-300

ISBN: 979-10-300-0174-7

ISSN: 0007-4640

\section{Referencia electrónica}

Álex Matas Pons, «El paisaje urbano moderno y la tradición literaria española», Bulletin hispanique [En línea], 117-1 | 2015, Publicado el 01 junio 2018, consultado el 11 febrero 2022. URL: http:// journals.openedition.org/bulletinhispanique/3857 ; DOI: https://doi.org/10.4000/bulletinhispanique. 3857 


\title{
El paisaje urbano moderno y la tradición literaria española. Visiones desde la torre en la obra de Clarín y Galdós
}

\author{
Álex Matas Pons \\ Universidad de Barcelona
}

Lobjet de cet article est l'analyse du paysage urbain dans les lettres hispaniques. Deux exemples concrets, pris dans les œuvres de Clarín et Galdós, montrent comment le paysage urbain capte de manière dynamique un espace instable et se détache de la fixation statique et ordonnée d'une scène conventionnelle.

Mots-clés : paysage urbain, littérature urbaine, Leopoldo Alas Clarín, Benito Pérez Galdós.

Este artículo analiza el paisajismo urbano en las letras hispánicas. A partir de dos ejemplos concretos de la obra de Clarín y Galdós se analiza cómo el paisaje urbano capta de manera dinámica un espacio inestable y se desmarca de la fijación estática y ordenada de un escenario convencional.

Palabras clave: paisaje urbano, literatura urbana, Leopoldo Alas Clarín, Benito Pérez Galdós.

This article wishes to analyse urban landscape in Hispanic literature. Based on two specific examples of Clarín and Galdós, the article examines how urban landscape captures an unstable space in a dynamic way and disassociates from the static and orderly setting of a conventional scenario.

Keywords: Urban Landscape, Literature and City, Leopoldo Alas Clarín, Benito Pérez Galdós.

\section{El paisaje uRbano: La Visión PANORÁmica de La CiUdad}

La representación romántica del paisaje supuso una auténtica revolución artística que rompió con el orden clásico. No se trataba tan sólo de una nueva predilección temática, sino de un factor determinante en una emergente 
concepción de la subjetividad. Los mismos autores del período romántico así lo entendieron y en 1831, Carl Gustav Carus, en sus Cartas sobre la pintura de paisaje, afirma taxativamente: «Los tiempos antiguos, dotados de un gran talento en el campo del arte y la ciencia, no nos han transmitido nada por lo que respecta a la pintura paisajística» ${ }^{1}$. Si se piensa en los más emblemáticos iconos de la cultura romántica, como por ejemplo en el Viajero sobre el mar de niebla de Gaspar David Friedrich o en el poema de Leopardi L'Infinito, resulta evidente que el arte del paisaje no consistía tanto en captar visualmente una realidad objetiva como en mostrar el movimiento que suscita esta realidad en el pensamiento y la imaginación de quien la observa. «El arte -dice Friedrich- no puede tener como fin la imitación; una meticulosa elaboración limita la fuerza de imaginación del observador; la pintura debe limitarse a ser alusiva y, sobre todo, estimular el espíritu; debe dejar a la fantasía campo de acción, de manera que el cuadro no debe tener por fin la representación de la naturaleza, sino solamente su evocación. La tarea del artista no consiste en la representación fiel del cielo, del agua, de las rocas y los árboles; lo que debe espejear en la naturaleza es el alma y la sensibilidad del artista $\aleph^{2}$. Ante la experiencia del paisaje, la contemplación no podía ser jamás estática porque siempre venía acompañada del movimiento de la divagación o la evocación de quien se veía desbordado ante un paisaje cuyos límites apenas podía divisar y se veía, por lo tanto, incitado a imaginar.

Esta preeminencia en la pintura y la poesía del sujeto concuerda con la promoción de los valores de la subjetividad que la filosofía romántica sugirió. Precisamente, la subjetividad en las artes se asienta de un modo radical cuando nace el paisaje, a lo largo del siglo XVIII, y se concede todo el protagonismo al entorno natural. Como es sabido, el nacimiento del paisaje no consistió sólo en la aparición de la naturaleza en las artes, pues esto no sería nada novedoso, sino en su emancipación con respecto a la historia humana. El paisaje nace cuando deja de ser mero telón de fondo o simple decorado con el que enmarcar las acciones, sagradas o históricas, que protagonizaban los figurantes. Este gesto con el que el hombre se retira para ceder todo el protagonismo a la Naturaleza no fue posible, como explica Georg Simmel, hasta aquel momento de la modernidad en que se deja atrás todo sentir unitario de la naturaleza, como por ejemplo el que sintieron los adoradores religiosos de la Naturaleza o las orientaciones teleológicas de campesinos y estrategas durante la Antigüedad y la Edad Media. Fue necesario que la modernidad propiciara la «individualización de las formas de existencia», que disolviera las "originarias sujeción y ligazón en existencias propiamente diferenciadas» para que por primera vez se contemplara el paisaje a partir de la Naturaleza ${ }^{3}$. El gesto de la contemplación exige la retirada del

1. Citado en Paolo D’Angelo (ed.), La religión de la pintura. Escritos de filosofía romántica del arte, Madrid, Akal, 1999, p. 15.

2. Citado en ibidem, p. 21.

3. G. Simmel, "Filosofía del paisaje» en El individuo y la libertad. Ensayos de crítica de la cultura, Barcelona, Península, 1998, p. 177. 
hombre y lo hace invisible frente al protagonismo del paisaje, pero es su mirada la que está presente en la composición artística o literaria y la que convierte la Naturaleza en paisaje. En palabras de Claudio Guillén, «en el paisaje el hombre se vuelve invisible, pero no su mirada y acaso su construcción de un sentido» ${ }^{4}$.

Esta constitución del paisaje moderno en las artes no se verá, en lo fundamental, alterada, aunque sí padecerá múltiples modificaciones a lo largo de los siglos. $\mathrm{Ni}$ tan siquiera el relevo que supondría en la historia de la pintura y la literatura el hecho de que conforme avanzaba el siglo XIX el paisaje de la contemplación estética dejaba de ser la Naturaleza para pasar a serlo la naturaleza artificial de la ciudad implicó una alteración sustancial de esta tradición ${ }^{5}$. Si antes se mencionaban los dos iconos más emblemáticos del paisajismo romántico, $E l$ viajero sobre el mar de niebla y L'Infinito, ahora también se reconocerá el valor icónico de otras dos grandes obras del paisajismo moderno: el Boulevard des Capucines de Monet y el poema Paysage de Baudelaire. Los escándalos que acompańaron a estas dos obras, o episodios de la historia del arte, tienden a enfatizar su carácter revolucionario, pero sería más oportuno subrayar la continuidad que mantienen con la tradición paisajística. La pintura de Monet se expuso en la célebre exposición de 1874 , aquella muestra alternativa que tuvo lugar en el taller que Nadar tenía en el boulevard des Capucines y que ha pasado a la historia con el nombre de "primera exposición impresionista». El poema de Baudelaire, por su parte, se publicó en la primera edición de Lesfleurs du mal, en 1857, pero adquiere un valor programático cuando en la segunda edición del libro, la de 1861, encabeza la serie de poemas titulada Les Tableaux de Paris, una vez se han suprimido los poemas censurados en la primera edición.

El mismo año 1874 se dijo de Monet y del resto de los jóvenes pintores que se organizaron al margen de la exposición oficial del Salón parisino que eran pintores impresionistas, porque «no pintan el paisaje, sino la sensación producida por ese paisaje» ${ }^{6}$. La obra de Monet, en particular, ejemplifica esta descomposición del paisaje, resultado de la desfiguración de unos figurantes que ahora se han convertido en multitud gracias a que en el paisaje reina la distorsión que provocan los trazos irregulares del pincel. El Boulevard des Capucines presenta una vista de París a través de una ventana cuya superficie de cristal está mojada por las gotas de humedad que resbalan, y distorsionan así la imagen que se obtiene de la ciudad. Es evidente que el paisaje urbano es, otra vez, la mirada que contempla la ciudad, aunque ahora es verdad que el modo

4. C. Guillén, «El hombre invisible: literatura y paisaje» en Múltiples moradas. Ensayos de Literatura Comparada, Barcelona, Tusquets, 1998, p. 98.

5. Es excelente el análisis que hace de este momento Michel Collot en el capítulo «La crise du paysage» de su libro Paysage et poésie du romantisme à nous jours, Paris, José Corti, 2005. También es útil consultar el volumen que reúne las actas de dos coloquios acerca del paisaje urbano: G. Peylet, P. Kuon, B. Steinhauser (eds), Paysages urbains de 1830 à nos jours, Bordeaux, Presses Universitaires de Bordeaux, 2004.

6. Jules-Antoine Castagnary, «Exposition du Boulevard des Capucines. Les impressionnistes», citado en Victor I. Stoichita, Ver y no ver. La tematización de la mirada en la pintura impresionista, Madrid, Siruela, 2005. 
en que esta mirada es presentada como tema de la composición presenta una novedad fundamental: es una mirada condicionada por el mismo contexto (el cristal húmedo) de la percepción de la imagen.

Baudelaire, en su poema de 1857, ya había escrito una suerte de prólogo a la pintura paisajística de los impresionistas y la progresiva clausura de la profundidad y la perspectiva que estos pintores y sus seguidores llevarían a cabo en las artes plásticas. Si el paisaje urbano de Monet presentaba la «mirada condicionada" por el cristal húmedo de la ventana, los versos de Baudelaire presentaban el acto mismo de la creación, el proceso mismo de la imaginación liberadora. En los primeros versos de Paysage la contemplación paisajística de la naturaleza urbana se asocia a la tradición poética del Idilio y la Égloga, pero el gesto brusco con el que el poeta culminará el poema, al cerrar «cortinas, puertas y ventanas», revelará el carácter irónico de dicha asociación. De hecho, en realidad se trata de una parodia de la ingenuidad con la que el poeta habría querido inicialmente representar la ciudad según las normas propias del orden clásico:

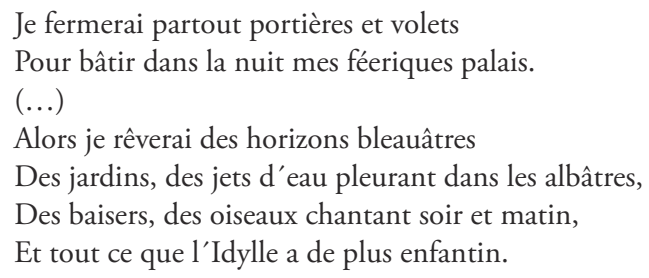

La imagen pastoril, estática y convencional, de la naturaleza antigua y la autoridad de la que gozó tradicionalmente ya no tienen ninguna influencia en los autores románticos o postrománticos. Desenmascarada la ingenuidad de esta voluntad inicial del poeta, el poema se convierte en una celebración del poder de la imaginación y la libertad creadora ${ }^{7}$. En consonancia, en 1859 Baudelaire acusaba con dureza a los paisajistas que habían expuesto sus obras en el Salón y lo hacía en unos términos que sólo pueden interpretarse como una declaración de su compromiso con la tradición paisajística que desde el Romanticismo había hecho de la imaginación y la sensibilidad del artista la única autoridad estética posible: «todo paisajista que no sabe traducir un sentimiento mediante un conjunto de materia vegetal o mineral no es un artista». Es la mirada del artista la que convierte la Naturaleza en paisaje, y este es el motivo por el que Baudelaire censura la pereza de imaginación de los paisajistas menores, al mismo tiempo que implora que le hagan volver «a los dioramas cuya magia brutal y enorme sabe imponerle una inútil ilusión». «Prefiero, dice, contemplar algunos decorados de teatro, donde encuentro artísticamente expresados y

7. Este poema ha sido ampliamente glosado. Para la cuestión del paisaje y la representación de la ciudad son imprescindibles el comentario que hace C. Guillén en «El hombre invisible: literatura y paisaje» y el análisis que hace K. Stierle en el capítulo "Le groupe des "Tableaux parisiens"” de su libro La capitale des signes. Paris et son discours, Paris, Éditions de la Maison des Sciences de l'Homme, 2001, p. 454-465. 
trágicamente concentrados mis sueños más queridos. Estas cosas, porque son falsas, están infinitamente más cerca de la verdad; en tanto que la mayor parte de nuestros paisajistas son mentirosos porque han desdeñado mentir» ${ }^{8}$.

El hecho de que Baudelaire defendiera el placer que brinda para la imaginación el orden de lo artificial ha significado que la existencia del paisaje urbano moderno muchas veces pasara desapercibido, pero ya se ha visto cómo en Paysage el gran poeta de la modernidad sellaba su compromiso con el paisajismo romántico al mismo tiempo que profesaba una imaginación liberadora. La crítica, sin embargo, ha preferido centrarse en el descenso del poeta a la calle, para convertirse allí en aquel flâneur con el que es comparado en Le peintre de la vie moderne (1863) y que Baudelaire describe como «un caleidoscopio cargado de conciencia, que, a cada uno de sus movimientos, representa la vida múltiple y la gracia moviente de todos los elementos de la vida " ${ }^{9}$. El estudio de la literatura urbana es un tema ya clásico en la teoría literaria y la literatura comparada, pero parece haber sucumbido a esta imagen. Es conocida, por ejemplo, la célebre contemplación de Manhattan desde la cima del ahora caído World Trade Center con que Michel de Certeau inicia el capítulo «Andares de la ciudad» en L'invention du quotidien (1980). Según Michel de Certeau, la imagen que se obtiene de la ciudad desde lo más alto de las torres es la imagen que antes quedaba reservada para «ojo de Dios» y no tendría nada que ver con el paisaje, sino con la ficción del conocimiento que querría mostrar lo inabarcable según la voluntad de dominio de la racionalidad urbanística. Para De Certeau sería necesario romper el hechizo de este simulacro «teórico» de la abstracción y descender de las torres para reencontrarse, gracias a un gesto que recuerda mucho al del «pintor de la vida moderna» del que habló Baudelaire, con los practicantes ordinarios de la ciudad y el uso espontáneo que estos hacen del espacio urbano ${ }^{10}$.

Esto ha hecho que cuando se ha analizado el panorama urbano de la modernidad, muchas veces se ha querido ver en él una estampa poética donde el dinamismo imaginativo inherente al paisajismo ya habría desaparecido. El panorama urbano, la contemplación de la ciudad, se convertía en un tópico por el que el mundo en contradicción quedaba ordenado, se convertía en una estampa tranquilizadora. Por el contrario, las letras europeas del siglo XIX presentan muchos ejemplos de paisajes móviles e inestables. Son muchas

8. Charles Baudelaire, «El Paisaje» en Salones y otros escritos sobre arte, Madrid, Visor, 1999, p. $273-280$.

9. Charles Baudelaire, «El pintor de la vida moderna» en Salones y otros escritos sobre arte, op. cit., p. 359.

10. Michel De Certeau, La invención de lo cotidiano 1. Artes de hacer, México D.F., Universidad Iberoamericana, 2007, p. 103-142. La misma imagen de la «práctica del andar» la volvemos a encontrar en el influyente texto de Fredric Jameson, El posmodernismo o la lógica cultural del capitalismo tardío (1984), bajo la denominación de «estética de trazado de mapas cognitivos». Ahora, sin embargo, no se trata tanto de un retorno a las prácticas medievales de los itinerantes viajeros de una época pre-cartográfica como de una proyección hacia un estadio más avanzado de una historia del progreso científico. 
las ocasiones en que un personaje se eleva hasta lo más alto de las torres de la catedral o de cualquier otro templo -ya que existen pocos miradores alternativos en una época en que las edificaciones laicas no pueden todavía competir en altura- y contempla un paisaje de imposible fijación. Elementos tan propiamente urbanos como la frenética actividad comercial del mundo del trabajo o los múltiples encuentros y desencuentros del irregular ritmo del paseo ocioso son los que con frecuencia determinan esta movilidad o inestabilidad e impiden una fijación, ordenada y jerarquizada del paisaje urbano.

Este paisaje urbano, el paisaje móvil e inestable de un mundo en contradicción, ha merecido menos atención por parte de la crítica. Y la atención ha sido todavía menor en el caso de la tradición literaria española. El olvido de la literatura urbana en las letras hispánicas puede que en parte se deba al hecho de que la proporción de textos de las diferentes literaturas ibéricas dependientes del fenómeno urbano sea menor que la de las grandes tradiciones europeas. Es verdad que resulta incomprensible la modernidad artística europea si no se presta atención al papel que jugaron en su gestación grandes metrópolis como Londres, París, Berlín o Viena. En estas ciudades no sólo tienen lugar transformaciones demográficas y urbanísticas de una dimensión mucho mayor que las que tuvieron lugar en España, sino que se convirtieron también en centros obligados de peregrinaje para una cultura artística cada vez más cosmopolita. Este cambio, por lo tanto, tuvo tanto que ver con las costumbres culturales de las masificadas poblaciones urbanas como con la función social que pasaría a desempeñar el artista desde entonces en adelante. Desde esta perspectiva, es cierto que el imaginario urbano de la literatura española ocupa un lugar excéntrico; secundario, si lo medimos con respecto a la modernidad europea. Sin embargo, el paisajismo urbano está también presente en la obra de los grandes autores del realismo español y las obras de Clarín y Galdós muestran la crucial función que desempeñó la picaresca no sólo en la concepción del paisaje que se observa en sus panoramas, sino también en la de sus contemporáneos europeos. A través de dos selectos ejemplos de estos dos grandes autores decimonónicos españoles, Clarín y Galdós, veremos cómo la tradición literaria espańola del siglo XIX, a pesar de carecer de un corpus de textos dedicados a la ciudad tan amplio y rico como el de otras tradiciones, se inscribe igualmente en la poética urbana de la modernidad literaria europea.

\section{Leopoldo Alas «Clarín»:}

VISIÓN DESDE LA TORRE DE LA CATEdRAL DE VetUSTA

El primero de los dos ejemplos es el inicio de la La Regenta (1884) de Leopoldo Alas "Clarín», cuyas páginas son bien conocidas:

La heroica ciudad dormía la siesta. El viento Sur, caliente y perezoso, empujaba las nubes blanquecinas que se rasgaban al correr hacia el Norte. En las calles no había más ruido que el rumor estridente de los remolinos de polvo, trapos, pajas y papeles que iban de arroyo en arroyo, de acerca en acera, de esquina en esquina revolando y 
persiguiéndose, como mariposas que se buscan y huyen y que el aire envuelve en sus pliegues invisibles. Cual turbas de pilluelos, aquellas migajas de la basura, aquellas sobras de todo se juntaban en un montón, parábanse como dormidas un momento y brincaban de nuevo sobresaltadas, trepando una por las paredes hasta los cristales temblorosos de los faroles, otras hasta los carteles de papel mal pegado a las esquinas, $y$ había pluma que llegaba a un tercer piso, y arenilla que se incrustaba para días, o para años, en la vidriera de un escaparate, agarrada a un plomo. ${ }^{11}$

Hay que recordar que es Fermín de Pas, el magistral de Vetusta, quien asciende ahora hasta la cumbre de la catedral para disfrutar del paisaje de la ciudad. Su llegada sorprende la tranquila contemplación paisajística de la ciudad por parte de dos "pilluelos» a los que «aquella altura se les subía a la cabeza y les inspiraba un profundo desprecio de las cosas terrenas». La llegada de Fermín de Pas es inesperada, aunque no es un accidente, ya que, como recuerda el monaguillo Celedonio, uno de los dos chicos, era frecuente ver «muchas tardes al señor Magistral subir antes o después de coro». Si se caracteriza por algo el Magistral y Provisor del Obispo, y esto a pesar de su cargo religioso, es por la mucha estima que le merecen las cosas terrenas. Es algo que si el lector no percibe en la primera caracterización del personaje brindada por el ascenso a las torres de la catedral, es fácil que sí perciba en una parecida caracterización que viene muy pocas páginas más adelante:

Uno de los recreos solitarios de don Fermín de Pas consistía en subir a las alturas. Era montañés, y por instinto buscaba las cumbres de los montes y los campanarios de las iglesias. En todos los países que había visitado había subido la montaña más alta, y si no las había, a la más soberbia torre. No se daba por enterado de cosa que no viese a vista de pájaro, abarcándola por completo y desde arriba. (...) Cuanto más subía más ansiaba subir; en vez de fatiga sentía fiebre que les daba vigor de acero a las piernas y aliento de fragua a los pulmones. Llegar a lo más alto era un triunfo voluptuoso para De Pas (...) Entonces sí que en sus mejillas había fuego y en sus ojos dardos. En Vetusta no podía saciar esta pasión; tenía que contentarse con subir algunas veces a la torre de la catedral. Solía hacerlo a la hora del coro, por la mańana o por la tarde, según le convenía. Celedonio que en alguna ocasión, aprovechando un descuido, había mirado por el anteojo del Provisor, sabía que era de poderosa atracción ${ }^{12}$.

En coherencia con el código de la novela realista, queda claro que el tópico queda subordinado a la caracterización del personaje. En particular, al carácter codicioso y la conducta del que, conforme avance el argumento de la obra, se desvelará como un evidente arribista. A pesar de esto, la presencia del tópico según el cual se ofrece una perspectiva de la ciudad desde una atalaya es significativa, como lo es también el diálogo más o menos explícito que mantienen estas páginas iniciales de la novela con El diablo cojuelo (1641), de Vélez de Guevara, que situó la acción de su novela en la madrileña Iglesia de San Salvador. Diálogo que antes de que lo hiciera «Clarín» ya habían mantenido con este mismo clásico de la picaresca española autores como Hawthorne o Dickens cuando ensayaron sus respectivas panorámicas urbanas. En la alusión

11. Leopoldo Alas «Clarín», La Regenta, Madrid, Castalia, 1990, p. 93.

12. Ibidem, p. 104. 
de La Regenta puede leerse que «el Magistral paseaba lentamente sus miradas por la ciudad escudriñando sus rincones, levantando con la imaginación los techos...», pero son todavía mucho más significativas las otras dos alusiones. La primera se lee en un relato de Nathaniel Hawthorne titulado «Sights from a Steeple», recogido en el volumen de cuentos Twice-Told Tales en 1837. En este relato leemos:

$O$ that the multitude of chimneys could speak, like those of Madrid, and betray, in smoky whispers, the secrets of all who, since their first foundation, have assembled at the hearths within! O that the Limping Devil of Le Sage would perch beside me here, extend his wand over this contiguity of roofs, uncover every mode of existence might be that of a spiritualized Paul Pry hovering invisible round and man and woman, witnessing their deeds, searching into their hearts, borrowing brightness from their felicity, and shade from their sorrow, and retaining no emotion peculiar to himself. But none of these things are possible; and if I would know interior of brick walls, or the mystery of human bosoms, I can but guess. ${ }^{13}$

La segunda de las alusiones a la novela de Vélez de Guevara en un panorama urbano es la que lleva a cabo Dickens en su novela Dombey and Son, publicada entre los años 1846 y 1848:

O for a good spirit who would take the house tops off, with a more potent and benignant hand than the lane demon in the tale, and show a Christian people what dark shapes issue from amidst their homes, to swell the retinue of the Destroying Angel as he moves forth among them. For only one night's view of the pale phantoms rising from the scenes of our too long neglect; and from the thick and sullen air where Vice and Feber propagate together, raining the tremendous social retributions which are ever pouring down, and ever coming thicker. ${ }^{14}$

El punto de partida de todos estos textos es el momento en que en la novela de Vélez de Guevara el Diablo Cojuelo instruye al estudiante Cleofás y para ello levanta los techos de las casas. Ante el asombrado estudiante queda al descubierto este "gran teatro del mundo» madrileño:

Y levantando a los techos, por arte diabólica, lo hojaldrado, se descubrió la carne del pastelón de Madrid como entonces estaba, patentemente, que por el mucho calor estivo estaba con menos celosías, y tanta variedad de sabandijas racionales en esta arca del mundo, que la del diluvio, comparada con ella, fue de capas y gorras ${ }^{15}$.

En un primer momento parece ineludible la interpretación moral de los panoramas urbanos decimonónicos. La simple elección de la catedral o la torre de una iglesia podría interpretarse según un afán moralizador por el que enfrentar lo sagrado de las alturas a lo profano de las «cosas terrenas». Y según esta misma dialéctica, el panorama paisajístico desde la torre del templo sería

13. Nathaniel Hawthorne, «Sights from a Steeple» en Tales and Sketches, New York, The Library of America, 1982, p. 43.

14. Citado en Raymond Williams, The Country and the City, Londres, Chatto \& Windus, 1973, p. 155.

15. Luis Vélez de Guevara, El Diablo Cojuelo, Madrid, Alianza, 1995, p. 80-81. 
en gran medida la pretendida respuesta frente al caos y el desorden de estas enormes "grilleras", según leemos en La Regenta, que son las ciudades modernas. La perspectiva moral, al fin y al cabo, se caracteriza por el esfuerzo integrador e impone orden y estabilidad a la intrincada materialidad del mundo urbano, a su creciente diversidad y heterogeneidad. Además, el modo en que el narrador de La Regenta describe la torre de la catedral («poema romántico», un «índice de piedra que señalaba al cielo») recuerda la descripción que se hace en el conocido capítulo "Paris à vol d'oiseau» de la catedral de París en Notre-Dame de Paris (1837) de Victor Hugo. Pero las diferencias entre aquel panorama moral de la ciudad de París que se ejecuta desde las elevadas torres de su catedral y los panoramas de Clarín, Hawthorne o Dickens son evidentes. Si en la novela del autor francés el panorama de la gran ciudad moderna da en realidad la espalda al inabarcable paisaje de la modernidad y se refugia en el idealismo melancólico cuando lamenta la pérdida de la antigua «ville gothique entière, complète, homogène» ${ }^{16}$, estos otros panoramas evitan el recuerdo nostálgico y por ello es por lo que se inscriben deliberadamente en la tradición cómico-satírica prefigurada por el panorama urbano de la novela de Vélez de Guevara. Son paisajes que admiten la incapacidad formal por la que poder hacerse cargo de esta nueva modernidad urbana, pero rehúyen la rememoración de un supuesto pasado ideal.

Ante este nuevo paisaje abigarrado y caótico de la ciudad moderna, es verdad que la prosa de Dickens es la que parecería estar, en un primer momento, más cerca de la perspectiva moral. La oscuridad que se cierne sobre la ciudad, y que tanto recuerda al célebre inicio de Bleak House ( $F$ Fog everywhere») puede interpretarse como una imagen reiterada con la que el autor inglés muestra las consecuencias morales de la indiferencia que reina en las recién masificadas ciudades. En una masificada ciudad en la que cada uno es un extrańo para el otro, la niebla o la oscuridad son las encargadas de hacer indescifrables o de ocultar qué clase de relaciones y compromisos sociales o laborales existen en realidad entre ellos. Ahora bien, lejos del refugio melancólico, Dickens ensaya un nuevo modo de representación literaria, una nueva dramatización, capaz de hacer visible o comprensible tanto la naturaleza de estas ocultas relaciones como el papel que juegan las instituciones que las amparan. La inscripción en la tradición cómico-satírica es fundamental, porque la imagen del «diablo cojuelo» levantando los techos de las casas es ahora sustituida por el alma benigna del novelista ("a good spirit who would take the house tops off") que busca hacer comprensible lo que en una primera observación resulta inapreciable.

Todos ellos se inscriben, por lo tanto, en una tradición moderna ya instaurada tiempo atrás en la que lo cómico y lo satírico, según explica Mijail Bajtín en La cultura popular en la edad Media y el Renacimiento, desempeñaron una función esencial. Esta tradición, a la que pertenece también El diablo cojuelo de Vélez de Guevara, se alejó del moralismo de la parodia, tal y como éste se daba en un estadio previo al nacimiento de la modernidad. Hasta entonces, la parodia y el

16. Victor Hugo, Notre-Dame de Paris, Paris, Éditions Garnier Frères, 1961, p. 135. 
humor en general sí podían explicarse según el afán moralizador y cumplían con una función integradora. Esto significa que el mundo del exceso y la abundancia alternativo al mundo oficial de la Iglesia y el Estado cumplía con una función renovadora en la subversión carnavalesca, y se encargaba de celebrar la provisión de la tierra engendradora. Pero según la caracterización que hace el teórico ruso, las consecuencias del ejercicio paródico de la premodernidad son por lo menos ambiguas, porque, una vez finalizada la provisional subversión de la oficialidad durante la celebración de la fiesta, se da el reforzamiento de la ley. Es decir, se da la idea de la fuerza de unas reglas que han sido suspendidas sólo de forma provisional para ser luego restauradas con un valor normativo, si cabe, de mayor legitimidad. Con la modernidad, en cambio, la risa ha dejado de ser una risa provisional y restitutoria para ser la risa permanente propia de un tiempo histórico con un poderoso sentimiento de la contingencia. Ahora es la risa la que rehúye cualquier pretensión restitutoria porque su misión es la de ejercer la crítica de un modo permanente.

De este modo hay que interpretar el panorama urbano de la ciudad de Madrid en El Diablo Cojuelo, una vez el diablo ha levantado los techos de las casas y asistimos a la respuesta del estudiante don Cleofás ante la visión de esta «Babilonia española, que en la confusión fue esotra con ella segunda deste nombre».

Quedó don Cleofás absorto en aquella pepitoria humana de tanta diversidad de manos, pies y cabezas, y haciendo grandes admiraciones dijo:

- ¿Es posible que para tantos hombres, mujeres y niños hay lienzo para colchones, sábanas y camisas? Déjame que me asombre que entre las grandezas de la Providencia divina no sea ésta la menor. ${ }^{17}$

La imagen de la ciudad que queda a sus pies es la de lo "grotesco», según la clásica definición de W. Kayser: «la mezcla centrífuga de lo heterogéneo, la fuerza explosiva de lo paradójico, que son ridículas» ${ }^{18}$. El asombro del estudiante se debe tanto al número de habitantes como a la diversidad del espectáculo y su heterogeneidad, pero la aventura que están a punto de comenzar el diablo y su discípulo no persigue el fin de reintegrar lo "grotesco», sino que en realidad no es más que una visión paródica de lo que se entiende por bien y por mal, pues admite la ambigüedad de esta asombrosa realidad multifacética de la ciudad de Madrid. La visión desde la torre que se lee en la obra de Vélez de Guevara no parece por lo tanto estar al servicio de la moralización, sino que en realidad es la representación de una sociedad grotescamente estilizada y que tiene muy poco que ver ya con la caracterización estática de la idealización costumbrista. Lo grotesco no es estático en absoluto, y depende de imágenes capaces de representar lo móvil y lo contingente, la constante imperfección de la existencia. 
Si hay una obra que ilustra a la perfección en qué consiste el ejercicio paródico cuando éste se da según las nuevas convenciones de la tradición moderna es sin duda El Quijote. Y el mismo Bajtín ya señala en su estudio que la pareja de protagonistas cervantina es profundamente carnavalesca. En las páginas de la novela de Cervantes, sin embargo, no encontramos una panorámica urbana como la que leemos en El diablo Cojuelo, pero sí hay un fragmento que permite ilustrar también las implicaciones que tendrá la literatura humorística de la literatura española en la poética urbana de la modernidad europea. Se trata de la conocida parodia - un riguroso episodio carnavalesco- del gobierno de la Isla Barataria por parte de Sancho. El inicio del capítulo «De cómo el gran Sancho Panza tomó la posesión de su ínsula, y del modo que comenzó a gobernar» dice así:

¡Oh perpetuo descubridor de las antípodas, hacha del mundo, ojo del cielo, meneo dulce de las cantimploras, Timbrio aquí, Febo allí, tirador acá, médico acullá, padre de la poesía, inventor de la Música: tú que siempre sales, y, aunque lo parece, nunca te pones! A ti digo, joh sol, con cuya ayuda el hombre engendra al hombre!; a ti digo que me favorezcas, y alumbres la escuridad de mi ingenio, para que pueda discurrir por sus puntos en la narración del gobierno del gran Sancho Panza; que sin ti, yo me siento tibio, desmalazado y confuso. ${ }^{19}$

Es evidente que la invocación a Apolo, «ojo del cielo» es paródica, y que hay que entenderla según la revisión que hace Cervantes en su novela de los diferentes géneros históricos de la tradición poética. No es estrictamente una perspectiva desde el cielo de una ciudad, pero sí una incursión paródica en el espacio imaginario de la utopía renacentista y la "carnavalización», mediante el personaje Sancho Panza, de la figura del príncipe gobernante. Invocar paródicamente a Febo, «ojo del cielo», es tanto como admitir el fracaso de cualquier esfuerzo integrador que estuviera motivado por el afán moralizador. Aunque ahora este esfuerzo integrador no tenga tanto que ver con el espacio urbano, sí tiene que ver con la ensoñación civilizatoria en general y el esfuerzo integrador que caracteriza la utopía renacentista. En este sentido hay que interpretar las palabras de Sancho cuando después de haber contemplado el «grotesco» orden de lo humano le explica al Duque:

- Después que bajé del cielo, y después que desde su alta cumbre miré la tierra y la vi tan pequeña, se templó en parte en mí la gana que tenía de ser gobernador; porque ¿qué grandeza es mandar un grano de mostaza, o qué dignidad o imperio el gobernar a media docena de hombres tamaños como avellanas, que, a mi parecer, no había más en toda la tierra? Si vuestra señoría fuese servido de darme una tantica parte del cielo, aunque no fuese más de media legua, la tomaría de mejor gana que la mayor ínsula del mundo. ${ }^{20}$

Hay por lo tanto una contemplación desde lo alto, aunque no de una ciudad: «desde su alta cumbre miré la tierra»; y hay también una inversión paródica de 
la figuración ideal del orden divino, tal y como se lee en Noche Serena de Fray Luis de León: «Cuando contemplo el cielo,/ de innumerables luces adornado,/ y miro hacia el suelo/ de noche rodeado...». Existe, de este modo, la misma dialéctica que se daba entre lo sagrado de las torres de las iglesias desde las que se contemplaba la ciudad en las obras de Hawthorne, Dickens y "Clarín» y el espacio profano, desordenado e inabarcable, de la ciudad. Es decir, que existe la misma ausencia del afán moralizador cuando se enfrenta lo sagrado de las alturas a lo profano de las "cosas terrenas». La contemplación de la ciudad desde las torres de la catedral de Vetusta por parte de Fermín de Pas era un modo por el que caracterizar a este personaje, y como dijimos, el lector no tarda mucho en averiguar que se trata de un "arribista». Por este motivo la alusión a la novela humorística de Vélez de Guevara cobra tanta importancia, al igual que llama la atención muchas páginas más adelante una alusión también irónica a Noche Serena de Fray Luis durante el paseo solitario de Fermín de Pas: «Don Fermín no era aficionado a contemplar la noche serena; (...) ¡Las estrellas! ¡qué pocas veces las había mirado con atención desde que era canónigo...!! ${ }^{21}$ Las estrategias humorísticas y la tradición cómica de la literatura española en general están presentes por lo tanto en la caracterización de este personaje que otea la ciudad desde las torres de la catedral. Fermín de Pas, como es sabido, es caracterizado en función de su codicia y en él se resumen los principios del naturalismo literario que Émile Zola expuso en su ensayo de 1880 La novela experimental. Como otros clérigos protagonistas de las novelas del siglo XIX, Fermín de Pas muestra la paradójica condición del que preserva su castidad contra la más obvia de las leyes biológicas. Además, al determinismo de las leyes naturales, hay que sumar el determinismo de las leyes hereditarias, pues él al fin y al cabo obedece los designios de su madre que no vio «en el campo más que la explotación de la tierra». Si la ciudad no admite idealización es en definitiva porque no es más que su presa, y el rendimiento de la tierra es ahora el control político, social y económico de la ciudad de Vetusta. Los dos determinismos se conjugan de forma simultánea en la panorámica inaugural de la novela con la que comenzábamos este apartado, cuando el deseo por Vetusta es también deseo por Ana Ozores, la Regenta:

Celedonio que en alguna ocasión, aprovechando un descuido, había mirado por el anteojo del Provisor, sabía que era de poderosa atracción; desde los segundos corredores, mucho más altos que el campanario, había él visto perfectamente a la Regenta, una guapísima señora, pasearse, leyendo un libro, por su huerta que se llamaba el Parque de los Ozores; sí señor, la había visto como si pudiera tocarla con la mano, y eso que su palacio estaba en la rinconada de la Plaza Nueva, bastante lejos de la torre...¿Qué más? Con aquel anteojo se veía un poco del billar del casino... ${ }^{22}$

La contemplación del paisaje estático de una ciudad idealizada, homogénea y ordenada, no es propio de la poética urbana moderna, y es por este motivo por lo que son tan relevantes los modelos que brinda la tradición literaria humorística 
española y las formas heterogéneas de lo grotesco. Los paisajes urbanos de "Clarín», Hawthorne o Dickens son deudores de esa herencia, aunque por supuesto asuman las modalidades propias de una nueva realidad estética que se vio alterada por las modificaciones estructurales de carácter político, social y económico de la modernización histórica. Es así como la perspectiva aérea de la ciudad moderna prescinde de cualquier arreglo cuidadoso atento al orden o a la más mínima planificación simétrica. No aspira a moral ni a compendio alguno. Pretende, tan sólo, mostrar la fuerza permanente de lo eternamente mudable. Refleja lo impresionante y lo desconcertante de la variedad incontenible, aunque esto no signifique siempre necesariamente la irreversible inorganicidad de un paisaje definitivamente atomizado. Lo que distingue en verdad al paisaje urbano moderno del paisaje urbano de la estética premoderna no es exactamente la renuncia a la organicidad sistemática, sino su consciente admisión de la pseudo-organicidad inherente a cualquier formulación ordenada, su consciente admisión de su carácter artificial. En este contexto es como cabe interpretar la paisajística aérea y las panorámicas urbanas de la modernidad. La figuración paródica divisa un espacio imperfecto e inestable, y sugiere que la única síntesis posible de esta heterogeneidad sólo puede darse en rigor mediante las propias estrategias de la parodia. Es decir, mediante el artificio pseudo-orgánico que procura la plurivocidad y el plurilingüismo, según las palabras de Bajtín.

\section{Benito PéRez Galdós: visión desde el Campanario de Santa Cruz}

El otro gran representante del naturalismo español es Benito Pérez Galdós y también él escribió una panorámica ejemplar, esta vez de la ciudad de Madrid, desde la torre de una iglesia. En consonancia con lo que se decía aquí, Benito Pérez Galdós también observa la presencia de la tradición literaria española en la modernidad europea, y precisamente reclama esta herencia en el prólogo que escribe a la segunda edición de La Regenta, cuando al valorar críticamente el movimiento naturalista subraya que él lo interpreta como una «repatriación de una vieja idea ${ }^{23}$. Por un lado, la homologación que hace Galdós entre el Naturalismo francés y la tradición literaria del realismo español es por supuesto cuanto menos arriesgada, pero por otro lado, sí llama la atención que a pesar de haber realizado dicha homologación no deje de lamentar la pérdida de «socarronería» en el Naturalismo francés. Parece estar dando cuenta de la transformación que ha padecido en la poética moderna la antigua dialéctica entre lo sagrado de las alturas y lo profano de las cosas terrenas, al mismo tiempo que acusa al naturalismo francés de no ser del todo consecuente con esta transformación ni con las estrategias paródicas de la tradición humorística que la procuraron. Estrategias como las empleadas por Vélez de Guevara o Cervantes, y en última instancia también por Leopoldo Alas «Clarín».

23. Benito Pérez Galdós, Ensayos de crítica literaria, Barcelona, Península, 1972, p. 214-215. 
Es verdad que si se lee desde esta perspectiva el manifiesto naturalista de Zola, Le roman expérimental, es fácil apreciar que la finalidad que persigue este movimiento es básicamente una finalidad moral, aunque se inscriba esta vez en la novedosa órbita del idealismo científico y del positivismo modernizador:

\footnotetext{
¡Du moment où l'homme n'était plus pour nous qu'une machine animale agissant sous l'influence de l'hérédité et des milieux, nous tombions à un fatalisme grossier, nous ravalions l'humanité au rang d'un troupeau marchant sous le bâton de la destinée! Il faut préciser : nous ne sommes pas fatalistes, nous sommes déterministes, ce qui n'est point la même chose. ${ }^{24}$
}

Si el naturalismo no equivale al fatalismo es porque el estudio de las leyes de la herencia y del determinismo ambiental mediante la neutra y fría mirada científica del novelista persigue el objetivo de conducir o controlar su influjo negativo. En realidad, no hay gran diferencia entre aquel hombre abstracto, metafísico, que, según el mismo Émile Zola, correspondía a la era escolástica y teológica y este hombre natural, sometido a las leyes físico-químicas de esta nueva era científica. Esto es lo que parece haber detectado Benito Pérez Galdós, cuando recuerda la necesaria "socarronería», el necesario humorismo hispánico: está recordando que en la tradición literaria española la representación de lo «grotesco» había significado el abandono del credo regenerador, propio en aquel tiempo del inmediato carnaval premoderno; pero es verdad que la poética naturalista no parece haber abandonado por completo el credo regenerador. La representación de lo "grotesco" admite la imperfección desde el mismo momento que reniega del paisaje estático, y gracias a las estrategias paródicas recuerda la inutilidad de cualquier pretensión que no sea ya la de mostrar una desintegrada realidad multifacética, una realidad inherentemente ambigua.

La misma posición crítica de Benito Pérez Galdós es la que sostiene Jorge Luis Borges en un texto de creación literaria como «Del rigor de la ciencia». Un texto que posee una estructura paródica y ejemplifica qué clase de la combinación intertextual ha convertido a este autor en un lugar común de la teoría literaria, y en particular del postestructuralismo:

... En aquel Imperio, el Arte de la Cartografía logró tal perfección que el mapa de una sola Provincia ocupaba toda una Ciudad, y el mapa del Imperio, toda una Provincia. Con el tiempo, esos Mapas Desmesurados no satisfacieron y los Colegios de Cartógrafos levantaron un Mapa del Imperio, que tenía el tamańo del Imperio y coincidía puntualmente con él. Menos Adictas al Estudio de la Cartografía, las Generaciones Siguientes entendieron que ese dilatado Mapa era Inútil y no sin Impiedad lo entregaron a las Inclemencias del Sol y los Inviernos. En los desiertos del Oeste perduran despedazadas Ruinas del Mapa, habitadas por Animales y por Mendigos; en todo el País no hay otra reliquia de las Disciplinas Geográficas.

Suárez de Miranda, Viajes de varones prudentes, IV, cap. XLV, Lérida, $1658 .{ }^{25}$

24. Émile Zola, Le roman expérimental, en Euvres Complètes, Tome 9, Paris, Nouveau Monde, 2004, p. 360.

25. Jorge Luis Borges, «Del rigor de la ciencia» en Obras completas. Vol. II, Barcelona, Emecé, 1992, p. 443. 
El texto de Borges se construye sobre la idea de que cualquier fachada que pretenda para sí un significado recto, un presunto significado verdadero y unívoco, merece ser objeto de desconfianza. Y es en este punto donde el autor argentino coincide con las habituales teorías del discurso de la mayor parte de las corrientes intelectuales del siglo XX. La realidad, parece querer decir este texto, es demasiado multifacética para ser representada mediante un único lenguaje. Tan solo la intertextualidad inherente a la figuración paródica de lo grotesco podría añadirse ahora según lo visto en los panoramas urbanos modernos, es capaz de representar, iluminar, una realidad imperfecta en constante transformación. En el relato de Borges, la frustrada minuciosidad y exhaustividad del conocimiento cartográfico dibuja el rastro de un fracaso en la forma de la reliquia, las ruinas del frustrado mapa que ahora son habitadas por Animales y Mendigos. El hecho de que sean reliquias es fundamental, porque la reliquia revela el carácter sagrado y mítico del texto que el positivismo y el cientifismo -el Naturalismo también- pretenden escribir. Es decir, que revela la conformidad con el carácter sagrado y mítico de aquellos otros textos propios de la premodernidad, de aquella era escolástica y teológica que Zola creía haber dejado definitivamente atrás.

Jorge Luis Borges retoma bajo la forma cartográfica la conocida metáfora medieval de la naturaleza descrita como un libro cuya autoría correspondería a Dios. Esta metáfora, de enorme difusión tanto en la literatura religiosa como en la profana, interpreta que todo lo terrenal aparece prefigurado en un libro trascendental y, por lo tanto, necesariamente completo y perfecto ${ }^{26}$. Una metáfora que, según C. S. Lewis resume la cultura libresca y la tradición filosófica medieval, cuando se negaba aquella dialéctica moderna que enfrenta lo sagrado de las alturas a lo profano de las cosas terrenas, pues en aquella sintética mentalidad el saber desempeñaba una función armonizadora capaz de procurar una «organización total de su teología, ciencia e historia en un único modelo mental, complejo y armonioso del universo» ${ }^{27}$. Ahora, en la era científica del determinismo, por mucho que Zola pretende no ser fatalista, la figura del autor divino ha sido relevada al habérsele concedido el poder de la escritura al riguroso cartógrafo, pero pervive todavía un mismo modelo mental, «complejo y armonioso del universo».

Por todo ello Galdós reclamaba, no con tanta ingenuidad, que se prestara atención al humorismo de la tradición literaria española. Galdós, al igual que su contemporáneo Leopoldo Alas "Clarín", también escribió una ejemplar panorámica urbana. En su caso se trata de un texto periodístico de 1886, «Desde la veleta", y la ciudad representada es Madrid. Como en tantas ocasiones, la dialéctica de lo sagrado de las alturas y lo profano de las cosas terrenas vuelve a sugerirse con la simple elección del mirador: la iglesia de Santa Cruz. Y aunque esta vez no se trate tanto de la inscripción en una tradición literaria humorística

26. Véase el capítulo del clásico libro de E.R. Curtius, Literatura europea y Edad Media Latina, dedicado a este asunto: «El libro como símbolo», México, FCE, 1999, pp. 423-499.

27. C. S. Lewis, La imagen del mundo, Barcelona, Península, 1997, p. 17. 
mediante juegos paródicos o alusiones irónicas, como había sucedido en el caso de La Regenta, sí se da también el consentimiento con lo inabarcable y desordenado de las nuevas grandes metrópolis:

Qué magnífico sería abarcar en un solo momento toda la perspectiva de las calles de Madrid; ver el que entra, el que sale, el que ronda, el que aguarda, el que acecha, ver el camino de este, el encuentro, la sorpresa del otro; seguir al simón que es bruscamente alquilado para dar cabida a una amable pareja; verle divagar como quien no va a ninguna parte; verle parar depositando sus tórtolos allí donde un ojo celoso no se oculte entre el gentío; ver el carruaje del ministro, pedestal ambulante de dos escarapelas rojas, dirigirse a la oficina o a Palacio, procurando llegar antes que el coche del nuncio; mirar hacia la Castellana y ver la vanidad arrastrada por elegantes cuadrúpedos, midiendo el reducido paseo, como si el premio de una regata se prometiera al que da más vueltas; sorprender las maquinaciones amorosas que en aquel laberinto de ruedas se fraguan durante el momentáneo encuentro de vehículos; ver al marido y a la mujer arrastrados en dirección contraria, rodando el uno hacia el naciente y el otro hacia el poniente, permitiéndose, si se encuentran, el cambio de un frío saludo; ver la gente pedestre en el paseo de la izquierda contemplando con envidia la suntuosidad del centro; seguir el paso incierto del tahúr que se encamina al garito; ver descender la noche sobre la villa y proteger en su casta oscuridad la pesca nocturna que hacen en las calles más céntricas las estucadas ninfas de la calle de Gitanos; oír la serenata que suena junto al balcón y contemplar la rendija de luz que indica la afición musical de la beldad que vela en aquella alcoba; esperar el día y ver la escuálida figura del jugador que, tiritando y sońoliento, entra en el café a confortarse con un trasnochado chocolate; ver los mercados abriendo al público sus pestíferos armarios; ver al sacristán moviendo el pesado cerrojo de la puerta santa y contar las primeras mojigatas que suben las sucias escaleras del templo; ver de quién es el primer cuarto que recoge el ciego en su mano petrificada; ver salir de una puerta un ataúd gallegamente conducido, y saber dónde ha muerto un hombre; ver salir a un comadrón y saber dónde ha nacido un hombre; ver... pero adónde vamos a parar.

¡Cuántas cosas veríamos de una vez si el natural aplomo y la gravedad de nuestra humanidad nos permitieran ensartarnos a manera de veleta en el campanario de Santa Cruz, que tiene fama de ser el más elevado de esta campanuda villa del oso! ¡Cuántas cómicas o lamentables escenas se desarrollarían bajo nosotros! ¡Qué magnífico punto de vista es una veleta para el que tome la perspectiva de la capital de España! ${ }^{28}$

Ya no hay alusión directa a El Diablo Cojuelo, pero el punto de vista de la veleta resume la movilidad necesaria para captar la confusión urbana y contradice cualquier estatismo. Además, la indiscreción del «diablo cojuelo» sí halla su equivalente en este "ojo celoso" que, oculto entre el gentío, espía a la pareja de tórtolos. Galdós se hace cargo aquí del nuevo factor determinante para la comprensión de las ciudades decimonónicas: el fenómeno de la multitud y el anonimato que procura el hecho de que unos sean extraños a los ojos de los demás. Confundiéndose entre la multitud, uno puede gozar del mismo anonimato y espiar con la misma impunidad con la que espiaban los protagonistas de la novela de Vélez de Guevara cuando levantan los techos de 
las casas. De hecho, si la panorámica no puede ofrecerse según el punto de vista de la veleta, entonces, parece sugerir ya Galdós, sólo podrá llevarse a cabo un ejercicio paisajístico satisfactorio desde la movilidad del paseante anónimo. Tan solo si se desciende de la torre del templo sagrado.

Si sugerimos que la única opción paisajística será a la larga el descenso a la calle y la asunción de la perspectiva de cualquier paseante es porque lo que sí se lee ya en el texto de Galdós es que la perspectiva única, de la que han dependido las estrategias clásicas de la composición paisajística desde el Renacimiento en adelante, ya no es posible. El oteador se ve obligado a admitir que es inviable ya la fijación de una escena que acontecería en un único momento, pues se ha hecho evidente que el paisaje urbano sólo existe en la medida en que se dan siempre múltiples temporalidades yuxtapuestas. Por este motivo el paisaje urbano desde la veleta de la torre de la iglesia de Santa Cruz se estructura en función del contraste de las diversas temporalidades y ritmos que articulan el denso espacio de la ciudad de Madrid. Vemos, por ejemplo, cómo una pareja se ve arrastrada por la multitud, y cómo uno de ellos es arrastrado hacia el "naciente» mientras que el otro es arrastrado hacia el "poniente». Y vemos también cómo el despertar de la ciudad acoge al mismo tiempo al recién nacido, según lo sugiere el caminar del comadrón, y al recién fallecido, según lo sugiere el ataúd "gallegamente conducido».

Un paisaje moderno de estas características ya no admite la aislada escena solemne y memorable, y todo parece estar sometido a las formas periodísticas de la caricatura humorística. Así, las «escenas lamentables que se desarrollan bajo nosotros» conviven necesariamente con las escenas cómicas. No sólo por los múltiples gestos cómicos de muy diversos protagonistas, como el de la "mojigata» ante la suciedad, sino también por la "cómica» carrera que mantienen el nuncio y el ministro por llegar antes a Palacio, con la que el autor resume con gráfico humor la realidad política decimonónica y las rivalidades económicas de los grupos de poder que compiten por liderarla. Esta parodiada rivalidad política y económica es tan cómica como esa otra carrera, mucho más trivial, que se está dando de forma simultánea en el Paseo de la Castellana, la que mantienen los vanidosos que se exhiben sobre sus «elegantes cuadrúpedos» ante la mirada envidiosa de los "míseros bípedos», como si fuera una regata y compitieran por ver quién es capaz de dar más vueltas que el otro.

El contrapunto entre escenas serias y cómicas, entre temporalidades enfrentadas, define la prosa urbana de la modernidad literaria. Explica la discontinuidad de una escritura que oscila entre la consolidación y la disolución de manera ininterrumpida, como esta muchedumbre que arrastra a los paseantes, pero que al mismo tiempo permite ocasionalmente el encuentro y el «frío saludo»; o esta frenética carrera de los carruajes, pero que al mismo tiempo permite de manera ocasional que se fragüen «maquinaciones amorosas» durante «el momentáneo encuentro de vehículos». Esta es la prosa capaz de recrear un espacio en el que nada se agrupa felizmente, como la misma veleta desde la que se observa la ciudad, movida por el viento, jamás se detiene en una única escena. Así lo da a entender la enumeración dictada siempre por 
verbos de movimiento (entrar, salir, aguardar, acechar, seguir, etc.) o por el uso anafórico del verbo «ver». Sólo el verbo «oír» interrumpe esta retórica hecha de constantes paralelismos, y lo hace para explicar que ni tan siquiera la noche y su supuesta invitación al descanso serán capaces de poner fin al movimiento. De noche escuchamos, por ejemplo, las canciones de amor, y hablan al lector de la noche en vela de los enamorados; y escuchamos también el tiritar del jugador que espera la apertura del café, y habla también al lector de su noche en vela. El texto, en definitiva, se estructura gracias al constante juego de anáforas y paralelismos alrededor del verbo «ver» y parece sugerir ya aquello que Georg Simmel ${ }^{29}$ detectará más adelante y que tanto llamará la atención de Walter Benjamin cuando lee el París de Baudelaire: la insistencia mucho mayor en la utilización de los ojos que la de los oídos como algo específico de la experiencia de la gran ciudad.

Este paisaje urbano de la ciudad de Madrid comparte características comunes con los grandes paisajes urbanos de la literatura europea y explica, además, cómo es el periodismo la modalidad literaria que está ensayando con un mayor éxito una nueva escritura capaz de representar la desjerarquizada y multifacética realidad de las grandes metrópolis. Esto es algo que se puede ver si comparamos el panorama aéreo de Galdós con un panorama aéreo que Dickens publicó en las páginas del semanario Master Humphrey’s Clock, una revista en la que aparecieron publicados de forma periódica algunos conocidos relatos del autor inglés, como Barnaby Rudge, una de sus dos novelas históricas, o The Old Curiosity Shop. El lector de la época ya estaba acostumbrado desde los tiempos del célebre The Spectator de Addison y Steele a aquel recurso por el que se atribuía la autoría de los poemas, relatos o ensayos del número que tenía entre sus manos a los miembros de alguna clase de club. En este panorama urbano de la ciudad de Londres desde la Catedral de San Pablo el lector asiste a las meditaciones del mismo Maese Humphrey, el presidente homónimo de este club, quien ha subido hasta la cúpula para contemplar el inabarcable espacio que se extiende a sus pies. Antes, sin embargo, el lector ha acompañado a Humphrey en su lento ascenso hasta esta nueva atalaya, y al igual que sucede en el caso de la Catedral de Vetusta y la Catedral de París en las mencionadas novelas de "Clarín» y Víctor Hugo, la Catedral de Londres también es descrita según los códigos del pintoresquismo, y una letanía de evocaciones y reflexiones hablan acerca de sus genios fundadores y de la grandiosidad de una empresa que se ha mantenido, como anclaje intemporal, impertérrita en el centro de la ciudad a lo largo de los siglos. La dialéctica entre lo sagrado de las alturas y lo profano de las cosas terrenas vuelve a estar presente aquí. Pero al igual que la veleta, que presidía el campanario de Santa Cruz, contradecía la inmovilidad sugerida por el templo sagrado, aquí será la fascinante maquinaria del reloj la que la contradiga, esta "complicada multitud de ruedas y cadenas de hierro y de bronce» ubicada en la cumbre que servirá de atalaya a Maese Humphrey:

29. Véase el artículo de Simmel, «Las grandes urbes y la vida del espíritu». 
I sat down opposite it, and hearing its regular and never-changing voice, that one deep constant note, uppermost amongst all the noise and clatter in the streets below-marking that, let that tumult rise or fall, go on or stop-let it be night or noon, tomorrow or today, this year or next-it still performed its functions with the same dull constancy, and regulated the progress of the life around, the fancy came upon me that this was London's Heart, and that when it should cease to beat, the City would be no more.

It is night. Calm and unmoved amidst the scenes that darkness favours, the great heart of London throbs in its Giant breast. Wealth and beggary, vice and virtue, guilt and innocence, repletion and the direst hunger, all treading on each other and crowding together, are gathered round it. Draw but a little circle above the clustering house-tops, and you shall have within its space, everything with its opposite extreme and contradiction, close beside. Where yonder feeble light is shining, a man is but this moments dead. The taper at a few yards' distance, is seen by eyes that have this instant opened on the world. (...) Does not this Heart of London, that nothing moves, nor stops, nor quickness - that goes on the same, let what will be done - does it not express the city's character well? $?^{30}$

Este paisaje presenta ya algunas de las características estilísticas recurrentes en las muchas descripciones que se hacen de la ciudad moderna en la novelística de Dickens. El modo en que emplea los paralelismos y las anáforas, al igual que hemos visto que hacía también Galdós, dota a la ciudad de aquella apariencia que tanto llamó la atención del director de cine ruso Sergei Eisenstein. Como es sabido, el cineasta veía en las escenas imaginadas por Dickens, sobre todo en aquella rutina de Coketown descrita en Hard Times, un antecedente inmediato de la técnica cinematográfica del montaje. Se yuxtaponen imágenes sin mediación alguna y se capta la atomización del paisaje urbano mediante la exacerbación de los contrarios - «opposite extreme and contradiction»-. Así hay que interpretar el hecho de que el mismo cirio ilumine simultáneamente la escena del nacimiento y la del fallecimiento, de idéntico modo al que hemos visto que se da también en la crónica de Galdós. Pero en ninguno de los dos casos es posible interpretarlo como un indicio de que lo contingente humano debe inscribirse en el conjunto natural de lo cíclico y el constante ir y venir de las estaciones del año. Esta sería la interpretación adecuada si este cirio iluminara estas mismas escenas en el espacio estático del mito, donde se evoca siempre a una sospechada causa primigenia, desconocida y misteriosa, pero subyacente a lo transitorio. Ahora, en cambio, esta causa primigenia parece ser el latido rítmico de la exacta y precisa maquinaria del reloj de la Catedral de Londres - "this was London's Heart, and that when it should cease to beat, the City would be no more-»; de este reloj artificial depende la vida de esta metrópolis descrita metafóricamente como un monstruo - "The great heart of London throbs in its Giant breast»-. Es la labor ininterrumpida de la maquinaria del reloj la que anima la actividad incesante de esta ciudad cubierta por la niebla, con la que Dickens ofrece el reverso de aquella otra panorámica de la ciudad de Londres que antes que él había escrito William Wordsworth en el poema Composed upon Westminster Bridge (1802), donde el «smokeless air» de

30. Charles Dickens, Master Humphrey's Clock and Other Stories, Londres, Everyman, 1997, p. 135-136. 
un luminoso amanecer permite la contemplación de la ciudad mítica animada por un «mighty heart». Una ciudad estática que ha sido capaz de sobrevivir a los azares de la historia y del tiempo:

\author{
Earth has not anything to show more fair! \\ Dull would he be of soul, who could pass by \\ A sight so touching in ts majesty: \\ This City now doth like a garment wear \\ the beauty of the morning; silent, bare, \\ ships, towers, domes, theatres and temples lie, \\ Open unto the fields, and to the sky, \\ all bright and glittering in the smokeless air
}

En el poema de Wordsworth los poderes comerciales (ships), artísticos (theatres), militares (towers) y religiosos (domes) conviven armónicamente, agrupados felizmente, en un paisaje calmo de quietud majestuosa. Frente a este paisaje inverosímil, la poética dickensiana, de la que también han dado cuenta «Clarín» y Galdós con su relectura de la tradición literaria española, propone otro paisaje hecho de novedosas soluciones formales. En este nuevo paisaje ya no hay cabida para la mirada totalizante ni para la perspectiva única, pues ya sólo podría interpretarse como un subterfugio ante la multiplicación de escenas parciales que componen el objeto de la representación; ante la multiplicación de visiones autónomas y diseminadas; ante la multiplicación de instantáneas en conflicto. El espacio metropolitano es el espacio de intersección de flujos dotados cada uno de ellos de su propia temporalidad, y el paisaje no es paisaje si frustra esta visión del desorden y el desconcierto.

\title{
Bibliografía
}

Baudelaire Charles, «El Paisaje» en Salones y otros escritos sobre arte, Madrid, Visor, 1999. Págs. 273-280.

- «El pintor de la vida moderna» en Salones y otros escritos sobre arte, Madrid, Visor, 1999, Págs. 347-392

Benjamin W., Poesía y capitalismo. Iluminaciones II, Madrid, Taurus, 1993.

Bajtín M., La cultura popular en la Edad Media y el Renacimiento. El contexto de François Rabelais, Madrid, Alianza, 2005.

Borges Jorge Luis «Del rigor de la ciencia» en Obras completas. El Hacedor, Vol. II, Barcelona, Emecé, 1992.

Collot Michel, Paysage et poésie du romantisme à nos jours, Paris, José Corti, 2005.

Curtius E. R., Literatura europea y Edad Media latina, México, F.C.E., 1999.

D’Angelo Paolo (ed.), La religión de la pintura. Escritos de filosofía romántica del arte, Madrid, Akal, 1999.

De Certeau Michel, La invención de lo cotidiano 1. Artes de hacer, México D.F., Universidad Iberoamericana, 2007.

Guillén Claudio, «El hombre invisible: literatura y paisaje» en Múltiples moradas. Ensayos de Literatura Comparada, Barcelona, Tusquets, 1998. Págs. 98-176. 
Izquierdo Luis, «Notas a una escena de Fortunata y Jacinta: sueño y tráfico urbano» en Díaz Larios, L. F. y Miralles, E. (eds.), Del Romanticismo al Realismo, Barcelona, Universidad de Barcelona, 1998. Págs. 557-567.

Kayser W., Lo grotesco, Nova, Buenos Aires, 1964.

Lewis C. S., La imagen del mundo, Barcelona, Península, 1997.

Pérez Galdós, Benito Ensayos de critica literaria, Barcelona, Península, 1972.

Peylet G., Kuon, P., Steinhauser, B. (eds), Paysages urbains de 1830 à nos jours, Presses Universitaires de Bordeaux, 2004.

Simmel G., «Las grandes urbes y la vida del espíritu», en El individuo y la libertad. Ensayos de crítica de la cultura, Barcelona, Península, 1998. Págs. 247-270.

- "Filosofía del paisaje» en El individuo y la libertad. Ensayos de crítica de la cultura, Barcelona, Península, 1998. Págs. 175-186.

Stierle Karlheinz, La capitale des signes. Paris et son discours, Paris, Éditions de la Maison des Sciences de l'Homme, 2001.

Stoichita Victor I., Ver y no ver. La tematización de la mirada en la pintura impresionista, Madrid, Siruela, 2005.

Williams R., The Country and the City, Londres, Chatto \& Windus, 1973.

Zola Émile, Le roman expérimental, en Euvres Complètes, Tome 9, Paris, Nouveau Monde, 2004.

Zubiaurre M. T., El espacio en la novela realista. Paisajes, miniaturas, perspectivas, México, F.C.E., 2000. 
